Volume 15 - Número 2 - ago/dez de 2020

\title{
COMPREENSÃO LEITORA, CONSCIÊNCIA SINTÁTICA E METACOGNIÇÃO SOB A ABORDAGEM DA PSICOLINGUÍSTICA EDUCACIONAL: UM ESTUDO COM O $7^{\circ}$ ANO DO ENSINO FUNDAMENTAL
}

\author{
READING COMPREHENSION, SYNTACTIC AWARENESS AND \\ METACOGNITION FROM THE EDUCACIONAL PSYCHOLINGUISTC \\ APPROACH: A STUDY WITH THE SEVENTH GRADE STUDENTS
}

\author{
Kátia Abreu ${ }^{1}$ \\ Katharine da Hora ${ }^{2}$ \\ Ana C. Pinheiro ${ }^{3}$
}

\begin{abstract}
RESUMO: O presente trabalho aborda o tema da compreensão leitora de alunos do sétimo ano do Ensino Fundamental. Foi feito um estudo longitudinal, tendo como base teórica os estudos de Kintsch e Rawson (2013), Perfetti, Landi, Oakhill (2013) e de Kato (1985, 1986), Morais (1996) e Maia (2018, 2019) e como base metodológica a técnica de Cloze divulgada por Taylor (1953), Santos et al (2004) e Santos, Boruchovitch, Oliveira (2009). O objetivo foi mostrar que as atividades de leitura realizadas por meio de ensino sistemático envolvendo metacognição, metalinguagem e consciência sintática podem conduzir ao aprimoramento da compreensão leitora. Foram aplicados dois testes de Cloze em etapas avaliativas, uma no início e outra ao final da pesquisa, além de cinco atividades durante a intervenção. $\mathrm{O}$ estudo sugere um crescimento significativo em compreensão leitora dos alunos no segundo teste, aplicado após a metodologia interventiva, apontando para um impacto positivo de ações pedagógicas baseadas em metacognição, metalinguagem e consciência sintática para o desenvolvimento da compreensão leitora.
\end{abstract}

PALAVRAS-CHAVE: Compreensão Leitora. Psicolinguística. Educação. Ensino Fundamental. Cloze.

\begin{abstract}
The present study addresses the theme of reading comprehension of seventh grade students. A longitudinal study was carried out, based on the theoretical studies of Kintsch and Rawson (2013), Perfetti, Landi, Oakhill (2013) and Kato (1985, 1986), Morais (1996) and Maia $(2018,2019)$ and Cloze technique methodology Taylor (1953), Santos et al (2004) and Santos, Boruchovitch, Oliveira (2009). The goal was to show that reading activities carried out through systematic teaching involving metacognition, metalanguage and syntactic awareness can lead to improvement of reading comprehension. Two Cloze tests were applied in evaluative parts of the research, one at the beginning and one at the end, in addition to five activities during the intervention. The study suggests a significant growth in students' reading comprehension in the second test, applied after the interventional methodology, pointing to a positive impact of pedagogical actions based on metacognition, metalanguage and syntactic awareness for the development of reading comprehension.
\end{abstract}

KEYWORDS: Reading Comprehension. Psycholinguistics. Education. Elementary School. Cloze.

\footnotetext{
${ }^{1}$ Katia Abreu - Professora do Departamento de Letras da Faculdade de Formação de Professores da Universidade do Estado do Rio de Janeiro; Pós-doutoranda do Programa de Pós-graduação em Linguística pela Universidade Federal do Rio de Janeiro. Email: kabreu00@gmail.com / Orcid: 0000-0002-8505-4512

${ }^{2}$ Katharine da Hora - Professora substituta do Departamento de Letras-Libras da Universidade Federal do Rio de Janeiro, Doutora em Linguística pela mesma instituição. E-mail: katharine.hora@,letras.ufri.br / Orcid: 000-00032288-1032

${ }^{3}$ Ana C. Pinheiro - Professora da Rede Municipal de Macaé (RJ); Mestra pelo Programa de Mestrado Profissional em Letras da Universidade do Estado do Rio de Janeiro. E-mail: anacpinheiro68@gmail.com / Orcid: 0000-00019608-3338
} 
Volume 15 - Número 2 - ago/dez de 2020

\section{Introdução}

No atual cenário da educação básica, com a recente homologação da Base Nacional Comum Curricular - BNCC (BRASIL, 2017), a área de Linguagens mantém o seu diálogo com documentos anteriores, por exemplo com os Parâmetros Curriculares Nacionais de 1998, e inova ao considerar as práticas contemporâneas de linguagem ligadas ao desenvolvimento das tecnologias digitais da informação e comunicação. Para os anos finais do Ensino Fundamental, o componente Língua Portuguesa se estrutura em um conjunto de habilidades que expressam as aprendizagens essenciais e se organiza em eixos, sendo um desses o Eixo Leitura que "compreende as práticas de linguagem que decorrem da interação ativa do leitor/ouvinte/espectador com os textos escritos, orais e multissemióticos [...]" (BRASIL, 2017:71). Nesse eixo, estão especificadas as dimensões das práticas leitoras como a reconstrução da textualidade, a reflexão crítica sobre as temáticas tratadas e validade das informações e ainda, as estratégias e procedimentos de leitura (BRASIL, 2017: 73-74).

O presente estudo se alinha com essa última dimensão e trata do aprimoramento da compreensão leitora à luz da Psicolinguística Educacional. Essa investigação foi pensada e desenvolvida com a finalidade de verificar se as atividades de leitura realizadas por meio de ensino sistemático envolvendo metacognição, metalinguagem e consciência sintática podem conduzir ao aprimoramento da compreensão leitora. A nossa hipótese é que com a etapa de rastreio, de avaliação da compreensão leitora, por metodologia interventiva composta pelo teste de Cloze e atividades de leitura, seja possível promover o desenvolvimento dessa compreensão.

Estudos sobre leitura e compreensão leitora apontam para o envolvimento de aspectos como objetivos, interesses e materiais de leitura (SOLÉ, 1998), processamento em diferentes níveis (KINTSCH e RAWSON, 2013), fatores superiores na compreensão e maquinário linguístico-conceitual (PERFETTI, LANDI e OAKHILL, 2013). Esse conjunto de aspectos aponta para a complexidade do processo de compreensão leitora e nos desafia a relacioná-los com a prática pedagógica da leitura. Essa pesquisa é, então, motivada pela dificuldade na compreensão leitora demonstrada por alunos do ensino fundamental em exames internos, exigidos no cotidiano escolar, e por exames externos, realizados pelas secretarias de educação.

Os baixos índices de compreensão leitora dos alunos brasileiros retratados por exames internos e externos, nacionais e internacionais, em escala restrita e em larga escala, não estão associados a um ponto específico, mas a descritores de desempenho agrupados em tópicos que formam, por exemplo, a Matriz de Referência de Língua Portuguesa do Sistema de Avaliação da Educação Básica (SAEB). Os resultados divulgados mostram que a habilidade média fica no nível 4, que seria o primeiro nível do conjunto de padrões considerados básicos pelo MEC, em uma escala dividida em níveis de 0 a 9 (BRASIL, 2019).

No presente artigo, vamos apresentar e discutir os resultados de um estudo experimental realizado no âmbito da educação básica, especificamente, no segundo segmento do ensino fundamental, em alinhamento com a investigação sobre o desempenho em leitura que foi desenvolvida, em parceria, no Laboratório LER/UFRJ.

O artigo está organizado da seguinte forma: Na seção II, abordamos compreensão leitora, consciência sintática e outras consciências, metacognição e metalinguagem na relação com o processamento da leitura. Na seção III, apresentamos o teste de Cloze como ferramenta de rastreio e como metodologia interventiva para a compreensão leitora. $\mathrm{Na}$ seção IV, apresentamos os resultados e conduzimos uma análise. Por fim, na seção V, fazemos as considerações finais do artigo. 
Volume 15 - Número 2 - ago/dez de 2020

\section{Compreensão leitora}

Os problemas de leitura podem derivar de fontes distintas (PERFETTI, 2001), partindo dos problemas de decodificação, de seleção forma-sentido, de sintaxe, específicos do sistema linguístico, chegando aos problemas de inferência, como apresentado no modelo arquitetônico do processo de leitura (PERFETTI \& ADLOF, 2012). Assim, a compreensão leitora se configura em um dos entraves, se não o principal, no desenvolvimento escolar dos alunos.

Ao tratarmos dos Anos Finais do Ensino Fundamental, vemos que a demanda de leitura de textos expositivos, com muitas informações e muito mais longos em relação àqueles dos livros didáticos dos Anos Iniciais, não está atrelada a uma capacidade de compreensão leitora, pois essa não é alcançada pela totalidade dos alunos, conforme verificado por Abreu e Hora (2019), em que as autoras observaram que alunos de nono ano do Ensino Fundamental tiveram baixos índices de compreensão leitora durante um teste de Cloze.

[...] o baixo índice de compreensão leitora demonstrado pelos alunos do teste deve-se a não adoção de um esquema de inspeção em conjunto, minimamente estruturante (MAIA, 2018) e da não utilização de conhecimentos gerais para realizar inferências, para relacionar diferentes elementos das proposições ou diferentes partes do texto. (ABREU e HORA, 2019, p. 199)

Nas turmas em que foi desenvolvida a presente pesquisa são poucos os alunos que leem por conta própria, fora do âmbito da escola. A maior parte da leitura em que esses alunos se engajam está limitada, nessa realidade, às atividades relacionadas às tarefas escolares.

Entretanto, um ponto importante que envolve a leitura no âmbito escolar é que, de conteúdo ensinado pela escola, ela passa a ser uma ferramenta de estudo, pois aprendemos a ler e depois passamos a ler para aprender. A leitura enquanto ferramenta necessária ao estudo das diversas disciplinas é de primordial importância para o avanço positivo do aluno na escola.

Segundo Morais (1996), o exercício da leitura tem um efeito sobre a capacidade de leitura e constitui um fator poderoso de diferenças individuais, porque tendo automatizado o processo de decodificação e criado um amplo vocabulário mental, liberamos a memória de trabalho para ocuparmo-nos da compreensão, para fazermos as conexões entre os sintagmas, as orações, os períodos e as diversas partes do texto. Depois de aprendido o código, é necessária a automaticidade para que se alcance a compreensão do material lido, pois é muito difícil compreender o que se lê quando a memória de trabalho está ocupada com a decodificação. Essa é a base, o alicerce primeiro em que se apoia a compreensão.

A partir de uma decodificação eficiente e automatizada podemos partir para atingir outros objetivos, dentre eles, a compreensão. Não que a compreensão não possa ser desenvolvida com quem ainda lê de forma lenta, vagarosa e com dificuldade, mas essa se torna muito mais fácil e produtiva para aqueles em que a decodificação do código alfabético não representa mais um problema. Em conformidade com essa visão, o Eixo Leitura do documento curricular indica o que deveria acontecer no ambiente escolar ao assegurar que "a participação dos estudantes em atividades de leitura com demandas crescentes possibilita uma ampliação de repertório de [...] conhecimentos que podem ser acessados diante de novos textos [...]" (BRASIL, 2017: 75).

Deste modo, decidimos lançar mão do teste de Cloze (Taylor, 1953) tanto para a etapa do rastreamento quanto para a elaboração da prática interventiva, em virtude da não interferência de uma possível opacidade dos enunciados de questões nas respostas dos alunos, sem desconsiderar outras características, como: fácil elaboração, aplicação e interpretação. Além disso, "essa técnica tem possibilitado identificar a capacidade do leitor de integrar a informação impressa que recebe ao conhecimento que tem da estrutura da língua" (CHANCE, 1985 apud JOLY et al, 2014: 224). 
O teste de Cloze é, em princípio, de fácil preparação e aplicação, pois requer um material básico para o professor e para os alunos como folha de papel, lápis ou caneta, mas que requer atenção tanto na seleção do texto a ser lacunado quanto no que diz respeito ao modo de considerar os resultados. A composição do teste de Cloze, nas etapas propostas neste estudo, lançou mão de texto autêntico, ou seja, "[...] é um material escrito, de qualquer natureza, veiculado socialmente, para satisfazer um propósito. São exemplos de textos autênticos os artigos de jornal, receitas, revistas, poemas e biografia" (GOMES; AUDI, 2013:120). Aqui, foram utilizadas narrativas de livros de literatura infanto-juvenil publicados no Brasil.

\subsection{Consciência sintática e outras consciências}

O modelo de leitura adotado na perspectiva deste estudo lida com aspectos cognitivos da leitura, o que significa dizer que considera a relação entre língua escrita e compreensão, memória e inferência, apontando para o ato de ler como atividade intelectual. Não só isso, porém, pois ressalta a função do texto na compreensão leitora que pode tornar o processamento mais fácil ou mais difícil (cf. KLEIMAN, 2004).

Se o processamento tem início na apreensão do objeto, no caso, o texto, pelos olhos, o término ocorre nos mecanismos de agrupamento desse objeto em unidades sintáticas. Essa finalização precede a atuação da inferência, enfim, da semântica na construção do sentido do texto.

Uma vez que o material visual é apreendido, começa a interpretação; das letras em sílabas e palavras, destas em frases, destas em proposições com significado. O material vai sendo estocado na memória de trabalho [...] que permite a organização em unidades sintáticas, segundo regras e princípios de nossa GRAMÁTICA IMPLÍCITA, isto é, o conhecimento que temos por sermos falantes da língua, que não equivale ao conhecimento gramatical adquirido na escola. (KLEIMAN, 2004:34)

É a consciência sintática que está centrada na habilidade de refletir sobre a estrutura gramatical interna das sentenças (GOMBERT, 1992) e que, aliada à memória de trabalho, promove o momento da segmentação, ou melhor, da organização em unidades significativas. Assim, é a consciência sintática que promove o fatiamento do texto (KLEIMAN, 2004), isto é, a divisão em unidades sintáticas e essa consciência permite ao leitor se apoiar nessas unidades do texto para chegar à compreensão.

Segundo Santos (2014), embora em número pequeno se comparado ao conjunto de pesquisas sobre consciência fonológica, as pesquisas realizadas sobre consciência sintática fornecem evidências de que existe uma correlação positiva entre a habilidade de refletir sobre a estrutura sintática da frase e o desempenho em compreensão leitora e escrita. Nessa perspectiva, no artigo em que apresentam a PCS (Prova de Consciência Sintática), Capovilla; Capovilla e Soares (2004) afirmam que

[...] além de contribuir para o reconhecimento de palavras, a reflexão sobre a sintaxe é essencial para a extração do significado do texto, uma vez que tal significado depende não somente da soma dos significados dos elementos lexicais individuais, mas também da forma pela qual tais elementos se articulam, o que é evidenciado por índices gramaticais como a ordem dos elementos na frase, a presença de palavras de função (e.g., preposições e artigos), a presença de morfemas gramaticais e a pontuação. (CAPOVILLA; CAPOVILLA E SOARES, 2004:40) 
Segundo Cain (2007), os resultados de pesquisas atuais apoiam a hipótese de que a consciência sintática pode facilitar o desenvolvimento da leitura de palavras no contexto; eles também sugerem que as relações entre consciência sintática e compreensão de leitura podem refletir a importância da memória e da linguagem para ambas.

No que diz respeito à consciência fonológica, caracteriza-se a habilidade de refletir acerca dos sons que compõem as palavras, de ser sensível à unidade mais elementar do idioma: a unidade fonológica. Isso auxilia no processo de decodificação que, por sua vez, contribui para a compreensão leitora.

Para a consciência morfológica, considera-se a habilidade de refletir sobre os morfemas, menores unidades linguísticas com significado próprio. Essas consciências auxiliam no reconhecimento dos itens lexicais durante a leitura, de modo que o leitor associa seu conhecimento sobre o fonema e sobre o morfema ao contexto dado por outros itens lexicais e sentenças presentes no texto.

Essas três consciências abrangem aspectos restritos ao sistema linguístico e, em perspectiva holística, são contempladas no teste de Cloze. As outras duas consciências (metatextual e pragmática) abrangem aspectos que vão além dos componentes do sistema linguístico. A consciência metatextual refere-se à habilidade de refletir sobre as propriedades dos textos: estrutura, organização e variedade de gêneros, já a consciência pragmática refere-se à relação entre o sistema linguístico e o contexto no qual a linguagem se insere.

Por fim, esclarecemos que a escolha pelo foco na consciência sintática deve-se à função que ela ocupa no teste de Cloze e a atividade de preencher um texto trabalhado com essa técnica colabora no desenvolvimento da aquisição da consciência metalinguística, pois leva o leitor a analisar de maneira consciente as palavras, as frases, as orações, os períodos e o texto, tornando a linguagem foco de atenção e objeto de análise e reflexão deliberadas.

Na relação do teste de Cloze com o processamento da leitura, especificamente no que tange à compreensão, discute-se sobre o que o teste acessa de modo essencial: um conhecimento global contextual ou um processamento local imediato, na elaboração das respostas (SANTOS et al, 2002). "Devido ao caráter multifacetado dos processos envolvidos na leitura, não é uma tarefa simples mensurar a relação entre testes de compreensão e os processos cognitivos que eles avaliam", conforme ponderação feita em Abreu et al, 2017: p. 1789.

Então, tendo em mente que se trata de uma técnica off-line, ou seja, em que a escolha por uma palavra que vai completar a lacuna ocorre após a leitura - em oposição a técnicas online em que a obtenção de uma medida ocorre durante a leitura, por exemplo - quando apresentamos a compreensão leitora analisada por Cloze, consideramos a que ocorre em nível local - parte - e que, cumulativamente, se expande em nível global, - todo. Considerar o nível local significa dizer que se está levando em conta cada trecho em que havia uma lacuna e o leitor considerou o item anterior e o item posterior à lacuna para completá-la (análise sintática). Por outro lado, considerar o nível global significa dizer que se leva em conta a leitura feita pelo leitor dos trechos que se acumulam e compõem um todo (fase pós-sintática).

Cabe reconhecer que, no teste de Cloze os dados tidos como "locais" ou "globais" serão derivados após a reflexão, ou seja, em que já houve a integração de todos os níveis de consciência, porém isso é significativo no momento em que estamos lidando com o ensino fundamental e que conhecemos o modo de avaliação de compreensão leitora praticado na escola. Os alunos, na condição de leitores, são expostos a um texto sobre o qual são feitas perguntas de compreensão e/ou interpretação e a análise das respostas dadas, que ocorre ao final da leitura (ou suposta leitura) do texto, demonstra como e se o texto foi compreendido.

Quando o leitor lê e relê o texto e o analisa conscientemente, controlando a sua leitura, "indo e voltando" no texto para conferir suas respostas, fazendo uma leitura com o objetivo definido de completar as lacunas, buscando perceber a adequabilidade ou não de uma determinada palavra em uma lacuna, ele está exercendo controle sobre a sua aprendizagem 
Volume 15 - Número 2 - ago/dez de 2020

naquele momento, refletindo sobre seus acertos e dificuldades para preencher as lacunas, está envolvido em um processo de metacognição. Metacognição e metalinguagem trabalham juntas quando o leitor se exercita com o teste de Cloze.

\subsection{Metacognição e metalinguagem}

O termo metacognição, a partir de sua etimologia, significa 'para além da cognição', 'a faculdade de conhecer o próprio ato de conhecer' e muitos teóricos contribuíram tanto para a sua compreensão quanto para a sua relação com a aprendizagem, porém os estudos realizados por Flavell e, em seguida, por Brown a partir dos anos 70 ocupam posição de destaque (RIBEIRO, 2003). As pesquisas desenvolvidas por eles apontam a existência de duas formas de entendimento sobre o que seria metacognição: 'conhecimento sobre o conhecimento' e 'controle ou autorregulação'.

Embora sejam duas formas, elas se encontram bem relacionadas, pois a metacognição apresenta a parte estável correspondente ao conhecimento sobre os próprios recursos cognitivos e a parte instável correspondente a regulação do conhecimento. Esse conhecimento exige "um envolvimento ativo do aprendiz na aprendizagem" (RIBEIRO, 2003: p. 113). Nas palavras de Poersch (1998:08), "constitui metacognição: saber o que se sabe e como se sabe."

Ribeiro (2003) comenta sobre o papel do professor como mediador na aprendizagem e como promotor da autorregulação e cita Brown (1987) para quem esses profissionais exercem papel indispensável na preparação dos alunos. Uma orientação metacognitiva na prática pedagógica tem o potencial de promover a autorregulação por meio da qual o aluno desempenha um papel ativo na formação de seu conhecimento e é capaz de desenvolver habilidades. Por esse motivo, a metacognição apresenta uma importância específica para a aprendizagem formal na escola.

No campo da aprendizagem, focalizamos a leitura que, como uma atividade multifacetada, requer não somente cognição, mas também metacognição capaz de atuar no desempenho da compreensão leitora (SPORER et al, 2007 apud RIANY 2010). Por exemplo, a compreensão leitora alcançará um nível ótimo se os alunos estiverem mais metacognitivamente atentos durante a leitura (ISRAEL et al, 2005 apud RIBEIRO 2003). A adoção de estratégias metacognitivas podem possibilitar ao aluno o planejamento e o monitoramento da sua tarefa de leitura, o que provavelmente contribuirá para a compreensão leitora. Conforme Maia (2019) assinala

Há, de fato, muitas evidências de que se refletir sobre a linguagem como objeto do pensamento, seja como atividade metalinguística, analisando e descrevendo aspectos da gramática, seja como atividade metacognitiva, avaliando-se os processos psicolinguísticos da produção ou da compreensão de palavras e frases, têm, inegavelmente, um impacto significativo na alfabetização e no letramento pleno. (MAIA, 2019b: 95)

Enquanto a metacognição tem como ponto central a cognição, no caso da metalinguagem o ponto central é a linguagem. Segundo Spinillo, Mota, Correa (2010) é quando a linguagem se torna objeto de reflexão e análise; tornando-se ela própria o foco de atenção deliberada por parte do indivíduo. Ao explicitamente focalizar sua atenção na linguagem, o indivíduo torna-se capaz de analisá-la e de manipulá-la, a partir de um monitoramento intencional. A figura 1, abaixo, ilustra a relação adotada neste estudo entre metacognição, metalinguagem e as consciências, com base em Gombert (1992). 
Figura 1 - Relação entre metacognição, metalinguagem e consciências

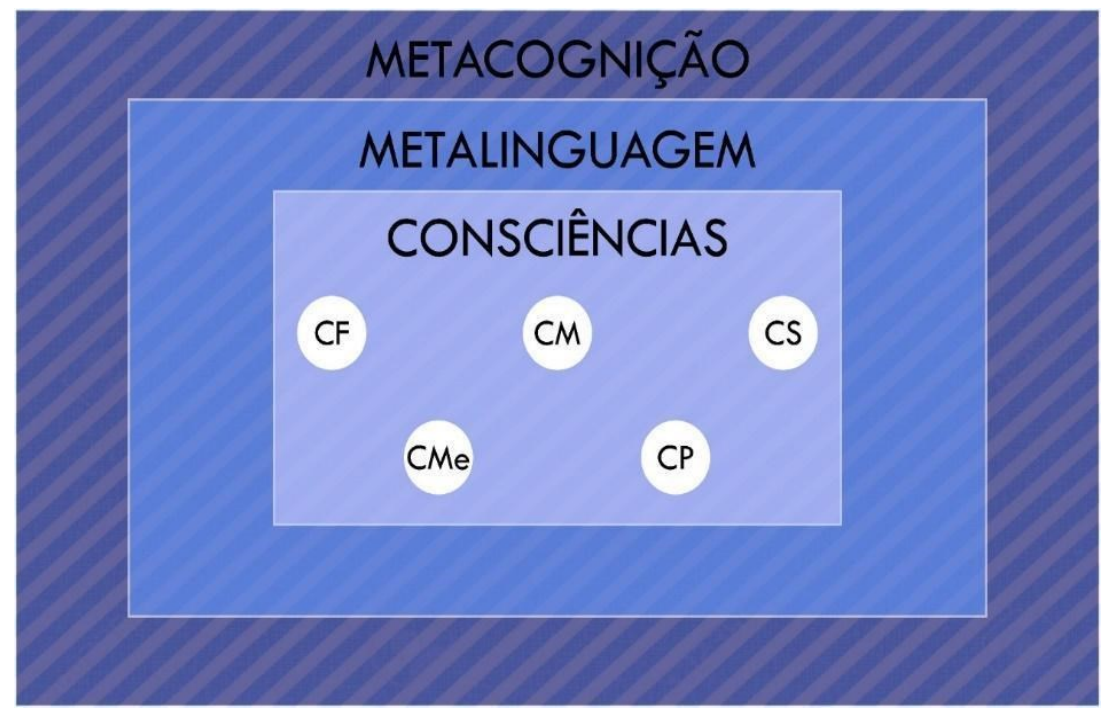

Fonte: as autoras (2020)

Consideramos que metacognição e metalinguagem estão relacionadas em essência, sendo que a metacognição concentra-se no processo e a metalinguagem no produto das atividades. Pelo viés da Psicolinguística, relacionamos a consciência linguística e suas ramificações: consciência fonológica, morfológica, sintática, metatextual e pragmática (SPINILLO, MOTA, CORREA, 2010; GOMBERT, 1992) com a compreensão leitora.

\section{Teste de Cloze}

O teste de Cloze foi idealizado por Wilson L. Taylor, em 1953. Esse teste integra o período dos novos estudos de leiturabilidade (DUBAY, 2004) cujo objetivo principal era medir a compreensibilidade de um texto escrito. DuBay (2004) afirma que "a introdução do teste de Cloze por Wilson Taylor em 1953 abriu o caminho para os pesquisadores testarem as propriedades dos textos e leitores com mais precisão e detalhes" (DUBAY, 2004: 27). Assim, o teste de Cloze é considerado como um instrumento para avaliação da compreensão em leitura.

Segundo Abreu et al (2017, p. 1769), nos últimos quarenta anos, essa técnica vem sendo usada no Brasil como instrumento de diagnóstico da compreensão em leitura e como instrumento de intervenção, por possibilitar aos pesquisadores a interpretação dos resultados e a possibilidade de escalonar os participantes por nível de desempenho e aos participantes, durante a prática interventiva, a possibilidade de prever o que está omitido tomando como base o seu conhecimento prévio e o seu conhecimento das estruturas linguísticas.

Em sua apresentação original, esse teste consiste na seleção de um texto com 200 a 250 vocábulos, do qual suprime-se, a cada cinco vocábulos, o quinto, sistematicamente. Desse modo, ele lida com palavras funcionais e com palavras lexicais. O primeiro e o último parágrafos do texto são mantidos intactos e nos parágrafos intermediários, em lugar das palavras suprimidas, são colocadas lacunas proporcionais ou não ao tamanho da palavra que se suprimiu. "Os examinandos devem preencher a lacuna com a palavra que julgarem ser a mais apropriada para a constituição de uma mensagem coerente e compreensiva" (SANTOS et al, 2002, p. 550). Tradicionalmente, a pontuação no teste é obtida pela soma das lacunas preenchidas corretamente.

Variações sobre essa técnica têm sido efetuadas por diversos pesquisadores (SANTOS, BORUCHOVITCH, OLIVEIRA, 2009; JOLY et al, 2014;) no que tange à eliminação dos 
vocábulos, como o teste em que as omissões não seguem o critério fixo do Cloze tradicional, da quinta palavra suprimida, mas são feitas escolhas de palavras a serem omitidas de acordo com critérios determinados por objetivos a se atingir (Cloze racional).

No que tange às respostas também existem variações.

$\mathrm{Na}$ versão clássica, as respostas são abertas, ou seja, o participante pode escolher qual palavra que preenche a lacuna corretamente. Em versões modificadas, as respostas são fechadas, ou seja, o participante terá de escolher, entre as alternativas oferecidas, aquela que preenche a lacuna corretamente. [...] Os defensores dessa proposta argumentam que o uso de respostas fechadas torna o teste mais prático em termos de pontuação. (ABREU et al, 2017, p.1774)

Quanto à correção dos itens do teste, existem três formas de correção: a literal, a sinônima e a ponderada. Segundo Santos, Boruchovitch, Oliveira (2007), a correção literal considera como acerto a lacuna preenchida com a palavra exata que foi omitida, inclusive em termos ortográficos. A correção sinônima aceita como correto o preenchimento da lacuna por um sinônimo da palavra que foi omitida e a correção ponderada, a avaliação da resposta é feita através da ponderação, considerando se a resposta dada pelo participante se aproxima ou não do esperado, de acordo com o contexto, não havendo a preocupação com a correção ortográfica.

A forma mais utilizada é a correção literal, tendo como critério de pontuação atribuir-se um ponto para cada lacuna corretamente preenchida e zero para o erro. Esse tipo de pontuação sofre críticas, pois não pondera o acerto ou o erro em função da dificuldade de preenchimento das lacunas, não levando em consideração que a quantidade de acertos não está relacionada apenas com a habilidade dos estudantes, mas também com a dificuldade dos itens. Santos et al. (2002, p. 550) defendem que "[...] dois escores iguais em um mesmo teste de Cloze, de diferentes pessoas, podem não ter o mesmo significado". "Tudo depende das dificuldades das lacunas." (SANTOS, BORUCHOVITCH, OLIVEIRA, 2007, p. 43) Há, no entanto, outra forma de pontuação, a de julgamento por juízes, que visa mensurar o nível de dificuldade dos itens, objetivando um resultado mais preciso.

\begin{abstract}
Nesse caso, são atribuídos valores diferentes para cada item de acordo com o seu grau de complexidade. Esses valores são estabelecidos por especialistas em língua portuguesa chamados de 'juízes', os quais, após exame dos itens suprimidos, indicam os níveis de dificuldade, a saber: fácil, médio e difícil. Assim, presencia-se uma variabilidade na soma dos pontos, pois os itens classificados como fáceis recebem menos pontos, ao contrário dos itens classificados como difíceis que recebem mais pontos. (ABREU et al, 2017, p.1775)
\end{abstract}

De acordo com Santos, Boruchovitch, Oliveira (2007), três juízes devem considerar o contexto do texto para julgar a dificuldade para o preenchimento de cada lacuna. Para se chegar à concordância sobre o nível de dificuldade de preenchimento de uma lacuna - fácil, médio ou difícil - deve haver concordância entre pelo menos dois dos juízes no julgamento.

É necessário observar com atenção o nível de dificuldade no preenchimento das lacunas abertas, examinando um possível custo no processamento envolvido na sua resolução, a fim de que o teste indique a compreensão do leitor sobre o material aplicado. Segundo Santos, Boruchovitch, Oliveira (2009), o estilo cognitivo do leitor também interfere na compreensão.

Em relação aos processos cognitivos que o teste de Cloze põe em jogo, há duas concepções que têm polarizado o debate sobre esses processos que concorrem na resolução do teste, como aponta Santos et al (2002) 
Volume 15 - Número 2 - ago/dez de 2020

Storey (1977) descreve que, nos últimos 25 anos, duas concepções têm polarizado o debate sobre quais processos cognitivos ocorrem na resolução do teste de Cloze. De um lado figuram pesquisadores que enfatizam o processamento global contextual como elemento central na elaboração das respostas. De outro, figuram os que enfatizam o processamento local imediato ou externo ao texto (conhecimento vocabular prévio) como elementos centrais de resposta. (SANTOS et al, 2002, p.552)

Segundo Santos et al. (2002, p. 552) determinado tipo de lacuna pode enfatizar o uso do contexto, comprovando a primeira posição, enquanto outra lacuna pode colocar em jogo a aplicação do conhecimento prévio, favorecendo a segunda posição. Bensoussan (1990, apud Santos et al, 2002) corrobora essa visão, afirmando que a leitura envolve simultaneamente o processamento top-down, pelo qual o leitor aplica seu conhecimento prévio ao texto e o processamento bottom-up pelo qual deriva significado das macroestruturas inerentes ao texto.

Entram em jogo então, no teste de Cloze, os dois tipos de processamento cognitivo que concorrem na compreensão de um texto, demonstrando sua relevância como recurso de avaliação na compreensão da leitura. Essa compreensão depende, entre outras variáveis, da habilidade do leitor em estabelecer relações entre os elementos do texto e, também, de sua capacidade em desenvolver associações apropriadas entre o conhecimento anteriormente adquirido e a informação expressa (RILEY, 1986, apud SANTOS et al, 2002).

Muitos estudos já têm demonstrado as possibilidades de uso do teste de Cloze para a educação não só nos níveis fundamental e médio, mas também no nível superior. Além disso, consideram o intercâmbio de variáveis associadas ao assunto, o que acaba por envolver linguistas, educadores e psicólogos com um objetivo comum: promover a compreensão leitora (cf. Abreu et al para uma revisão).

\section{0 trabalho experimental}

O trabalho experimental caracteriza-se por ser "uma abordagem metodológica complementar' [...]", que entre outras vantagens, "permite ao pesquisador investigar indiretamente os processos cognitivos que dão luz à luz a produção e a compreensão de enunciados" [...] "analisar estatisticamente o comportamento de grupo de pessoas, objetificando medidas subjetivas como a percepção individual da gramaticalidade" (KENEDY, 2015:145). O instrumento psicométrico escolhido para testar e capturar uma previsão comportamental de compreensão leitora de alunos do $7^{\circ}$ ano do ensino fundamental foi o teste de Cloze.

Com a finalidade de familiarizar os alunos com o teste de Cloze, foi aplicado e corrigido juntamente com os alunos um modelo em que utilizamos o texto intitulado "Os dois amigos e o urso" (ALLIENDE \& CONDEMARÍN, 2005, p. 131). Nessa atividade não foram contabilizados erros e acertos pois o objetivo era o de tornar a tarefa familiar aos alunos. $\mathrm{O}$ texto foi projetado na parede e procedemos à discussão sobre que elementos serviram de base para que chegassem à palavra que completou a lacuna corretamente.

Percebemos que o modo pelo qual justificaram suas escolhas de palavras e discutiram a adequação ou não da palavra sugerida pelo colega no contexto revelava a utilização de estratégias voltadas a atingir o objetivo de leitura proposto pela atividade: ler para preencher corretamente as lacunas de um texto com coerência e coesão, observando as pistas estruturais do próprio texto. As considerações feitas pelos alunos indicam um conhecimento de gramática capaz de estabelecer o significado deduzível da estrutura morfológica do item lexical. Eles reconhecem os elementos formadores da estrutura morfológica e alcançam a compreensão pela análise linguística (ROSA, 2000).

Após a aplicação desse modelo, o primeiro teste de Cloze para coletar dados para a pesquisa foi aplicado. Em seguida a esse primeiro teste, iniciamos a fase interventiva em uma 
Volume 15 - Número 2 - ago/dez de 2020

das turmas. A nossa preocupação durante essa fase da intervenção era a de não corroborar com uma postura pedagógica como a apontada por Maia

Uma das questões que se tem identificado, no que diz respeito à capacidade de leitura $\mathrm{e}$ de escrita dos alunos é que o ensino escolar costuma ser, além de prescritivo, excessivamente terminológico, nomenclatural, sendo, via de regra, cobrada dos alunos a nomeação de fatos da língua. (MAIA, 2018: 105)

A expressão chave que norteou a nossa prática foi participação ativa dos alunos (MAIA, 2019). Em nossa intervenção, buscamos não só uma forma de atuar com os alunos que se diferenciasse de modos e de modelos fixos, mas uma forma que gerasse reflexão tanto nos alunos sobre os fatos da língua, quanto em nós sobre a prática docente.

Assim, a atividade teste e a atividade interventiva que tiveram como metodologia o uso da mesma técnica diferiam em relação à forma como os materiais eram apresentados aos alunos. Durante a atividade teste, os alunos liam e completavam as lacunas, individualmente, sem auxílio do professor, diferentemente do que acontecia durante a prática interventiva, em que a atividade era feita em conjunto entre os alunos e o professor e, não apenas a leitura, em que os alunos colocavam em prática sua aprendizagem ativa por meio das discussões, mas também nas análises das opções de preenchimento das lacunas apresentadas.

\subsection{Participantes}

A pesquisa foi realizada em duas turmas do $7^{\circ}$ ano do ensino fundamental. $\mathrm{O} 7^{\circ}$ ano tem uma importância especial neste ciclo de estudo escolar porque o ano imediatamente anterior a ele, o sexto ano, é considerado um gargalo no Ensino Fundamental, juntamente com o primeiro ano (ano correspondente à alfabetização), por exibirem altos índices de reprovação. O sexto ano traz em seu bojo uma quantidade significativa de mudanças para quem sai dos anos iniciais do ensino fundamental, como aumento do número de disciplinas e de professores, contato e adequação à metodologia de ensino das disciplinas, complexidade das informações trazidas pelos textos, aumento significativo na extensão dos mesmos e a necessidade de adaptar-se e/ou organizar-se em meio a todas essas mudanças. Isso sem proceder a uma lista exaustiva.

Consideramos, por isso, que aqueles que conseguiram atravessar esse "gargalo", essa "ponte estreita", alcançaram uma certa habilidade em leitura, haja vista a demanda de leitura pela qual tiveram que passar para atingir aprovação no sexto ano. Na medida em que os estudantes passam para séries intermediárias ou superiores, os conteúdos temáticos das distintas áreas de estudo aumentam em variedade e quantidade, de maneira que não podem ser transmitidos apenas oralmente pelo professor, nem retidos na memória de longo prazo, apenas pela escuta ou visualização. Assim, a leitura torna-se, progressivamente, a principal fonte de informação para o estudante interessado em processá-la em profundidade (ALLIENDE \& CONDEMARÍN, 2005).

Participaram da pesquisa 46 alunos, com frequência regular, de uma escola da rede pública municipal de Macaé, cidade situada na região Norte Fluminense do Estado do Rio de Janeiro. Todos os alunos cursavam o sétimo ano do ensino fundamental, no mesmo turno, sendo que 23 eram da turma A e 23 da turma B. A turma A foi objeto de estudo e a turma B constituiu o grupo controle.

Nessa escola, a divisão de alunos por turma costuma seguir o critério de idade em que se agrupam os menores em uma turma e os maiores (leia-se aqui repetentes e evadidos de outros anos que ainda não têm idade para seguir no curso noturno) em outra(s), dependendo do número de alunos para aquele ano. Desta forma, todos os alunos da turma A encontravam-se na faixa etária prevista para a série (12 anos), o que não é um fato comum nas escolas públicas; 19 deles estudavam juntos desde a alfabetização, alguns desde a pré-escola. 
Volume 15 - Número 2 - ago/dez de 2020

A turma B estabelecida como grupo-controle, era constituída por alunos repetentes, todos os alunos já haviam sido reprovados pelo menos uma vez: 14 alunos tinham 13 anos, 5 tinham 14 anos, 2 tinham 15 anos e 2 tinham 16 anos.

\subsection{Material}

O material do primeiro teste e do último teste foi composto por textos narrativos extraídos de livros de literatura infanto-juvenil. Optamos por usar no período entre a aplicação do primeiro teste e do último teste, cinco atividades de Cloze como fase interventiva que foram aplicadas na turma em que a pesquisa estava sendo realizada com os textos discriminados a seguir: "O bicho folharal" (conto), "A cidade dos resmungos" (conto), "O dono da bola" (excerto do livro com o mesmo nome), "O fazendeiro e seus filhos" (conto) e "Um amor maior" (conto). A escolha pelo gênero 'conto' atendeu ao currículo do ano escolar e à indicação de especialistas, conforme apresentado a seguir.

Para o primeiro teste, o texto escolhido foi "A despedida" de Fanny Abramovich e, para o último teste, o texto escolhido foi "Os dois vasos", uma lenda chinesa, de autor desconhecido. $\mathrm{Na}$ seleção dos textos, utilizamos o critério apontado por Cunha (1991) que mostra ser a narração mais agradável para as crianças dessa faixa etária (12 anos até a adolescência), visto que são evitadas as descrições e digressões longas e que não mantém relação com o fio da história. A autora ainda afirma que

Assim é importante a narrativa linear, com tempo cronológico (e não psicológico), sem cortes e voltas ao passado (flash-back) ou a cenas paralelas, sem "fluxos de consciência". Os recursos narrativos mais adequados à criança costumam formar o conto ou o romance de ação, nos quais predomina a intenção de distrair, sem outro compromisso que o de narrar uma história interessante. (CUNHA, 1991:99)

Consideramos, também, a recomendação de Joly et al (2014) que ao tratar da técnica de Cloze menciona a possibilidade de não só se utilizar textos de diferentes conteúdos, mas também textos de caráter literário.

O texto "A despedida", apresentava 37 lacunas e o texto "Os dois vasos" apresentava 39 lacunas. O número de lacunas foi diferente nos dois testes pois precisávamos controlar a pontuação total do teste, explicaremos melhor na seção "critérios de correção". Foram mantidos intactos o primeiro e o último parágrafos dos textos e abertas lacunas a partir do segundo parágrafo, de cinco em cinco palavras, em que o espaço demarcado era do mesmo tamanho em todas as lacunas. Esse procedimento de construção das lacunas chama-se procedimento de razão fixa (SANTOS et al, 2002) ou Cloze randômico.

\subsection{Procedimentos}

O estudo longitudinal realizado com 46 alunos ao longo de um ano letivo teve caráter exploratório. Antes de procedermos à pesquisa foi solicitada autorização à direção da escola. Tendo sido obtida, foi enviada aos pais uma carta contendo explicações sobre os objetivos da pesquisa e requerendo a autorização para que os alunos pudessem participar dela. Depois de autorizada a participação pelos responsáveis, explicamos aos alunos todo o processo da pesquisa, discorrendo sobre as atividades que fariam ao longo do ano letivo e esclarecendo que essas tarefas visavam conhecer melhor as suas habilidades em leitura.

No primeiro bimestre, rastreamos o desempenho em leitura dos alunos (Cloze inicial) e recolhemos informações dos pais sobre sua situação acadêmica e sobre seus hábitos de leitura (tanto em prática individual quanto em prática com o/a filho/a). Elaboramos um questionário 
sobre hábitos de leitura e vida escolar dos alunos e realizamos uma entrevista individual com eles para saber quais eram as suas expectativas relacionadas à leitura naquele ano letivo.

Realizamos, então, a aplicação de forma coletiva. Os testes foram aplicados na primeira aula do dia para evitarmos a possibilidade de os alunos cumprirem a tarefa apressadamente para saírem para o recreio ou para irem embora. A sala possuía ar-condicionado e os alunos estavam atentos às instruções dadas oralmente e escritas também no quadro. Os participantes receberam o texto e foram instruídos a lerem primeiro o texto integralmente e só então darem início ao preenchimento das lacunas as quais deveriam preencher com apenas uma palavra que julgassem que completaria o texto com sentido. Os alunos tinham cerca de uma hora e meia para realizarem a tarefa.

Nos bimestres intermediários, ou seja, segundo e terceiro bimestres, realizamos a etapa interventiva com uma das turmas: 23 alunos. Entraram em cena 5 atividades de Cloze e 4 atividades voltadas à leitura, intituladas: "a mala da leitura", "a leitura com hora marcada", "leitura compartilhada", "cantando, encenando, declamando se aprende a ler" intercaladas com atividades de Cloze (cf. PINHEIRO, 2018).

O último teste de Cloze foi aplicado em novembro do mesmo ano, após a fase de intervenção. $\mathrm{O}$ intento era compararmos os resultados de um e outro teste, aplicados em momentos diferentes da pesquisa, além de compararmos o desenvolvimento das turmas que passaram por práticas de ensino diferentes.

Alinhados com as ideias de Pilati (2017:48) “[...] se tais práticas estiverem desvinculadas de reflexão e compreensão por parte do aluno, isso não promoverá a aprendizagem.”, esperamos, a partir dos dados obtidos por esta pesquisa, observar diferenças de desempenho entre as turmas analisadas, já que uma delas passará pelo processo de prática interventiva feita em sala de aula com atividades de leitura que priorizam um ensino voltados à metacognição e metalinguagem e a outra não passará por esse processo.

\subsection{Critérios de correção}

Neste estudo, a correção foi realizada pelo critério da ponderação em que se contabilizaram como acertos os itens preenchidos com palavras que fizessem sentido no contexto e não apenas com as palavras que tivessem sido originalmente usadas pelo autor do texto. Foram acionados três juízes (FONSECA et al, 2011) professores doutores que lecionam em universidades, para julgarem o nível de dificuldade dos itens que preencheram as lacunas, tendo sido contabilizada a pontuação dos itens, conforme as tabelas abaixo.

Tabela 1 - Pontuação do teste "A despedida"

\begin{tabular}{|l|l|l|}
\hline \multicolumn{3}{|c|}{ Pontuação do teste considerando a dificuldade do item } \\
\hline Itens & Quantidade de lacunas & Valor \\
\hline Baixa dificuldade & 20 & 20 (1 ponto cada item) \\
\hline Média e Alta dificuldades & 17 & 40 (2 ou 3 pontos cada item $)$ \\
\hline Total & 37 & 60 pontos \\
\hline
\end{tabular}


Volume 15 - Número 2 - ago/dez de 2020

Tabela 2 - Pontuação do teste "Os dois vasos"

\begin{tabular}{|l|l|l|}
\hline \multicolumn{3}{|c|}{ Pontuação do teste considerando a dificuldade do item } \\
\hline Itens & Quantidade de lacunas & Valor \\
\hline Baixa dificuldade & 20 & 20 (1 ponto cada item) \\
\hline Média e Alta dificuldades & 19 & 40 (2 ou 3 pontos cada item) \\
\hline Total & 39 & 60 pontos \\
\hline
\end{tabular}

Para que a pontuação total fosse a mesma nos dois testes houve a necessidade de abrir duas lacunas a mais no último teste, o que não impediu a comparação dos testes, já que as lacunas abertas foram lacunas de média ou alta dificuldade, que optamos por manter juntas na análise por considerar o limite entre uma e outra muito tênue.

No texto "A despedida" o tema versa sobre o momento de despedida que ocorreu entre uma criança e seu animal de estimação - um hamster - que havia morrido. Algumas lacunas exigiam a apreensão da informação contida na frase em que estavam inseridas (informação local imediata), para que o seu preenchimento fosse feito da forma correta como em "Cobriam a cova com terra.". Em uma perspectiva sintática, esperávamos que houvesse demonstração de ter sido feita a análise estrutural, em que o participante deveria preencher a lacuna com o determinante ' $a$ '.

Outras lacunas, porém, exigiam uma atenção à informação já oferecida e que deveria ser recuperada para que a lacuna fosse completada de forma adequada. Para chegar ao item "dor" no trecho "Com tristeza, com Zeca fez uma cruz...", por exemplo, era necessário desprender uma certa atenção ao que estava na linearidade da sentença e atenção à ideia de que a palavra "com" na expressão anterior formava uma locução adverbial de modo e que a palavra "com" repetida antes da lacuna indicava outra locução adverbial de modo "... com tristeza, com (dor)...”.

No texto "Os dois vasos", o assunto central é sobre dois vasos em estados diferentes, um inteiro e outro rachado. Assim como no primeiro texto, em algumas lacunas, os participantes tiveram que ter atenção à informação contida na frase em que estavam inseridas (informação local imediata) “... fim longa caminhada", em outros casos a atenção deveria ser dada ao contexto inicial "... enquanto aquele chegava meio vazio.", em que a informação de que um dos vasos estava rachado estava presente, dessa forma, o aluno saberia que deveria completar a lacuna com o termo "rachado".

Em alguns casos era necessário o uso da inferência, por exemplo no trecho "somente um vaso $e$ de água.", era necessário inferir que um dos vasos chegava com apenas metade da água que deveria conter, ou seja, era necessário relacionar o contexto de rachadura com a perda de água.

Para um preenchimento coerente das lacunas, os participantes precisam ler e analisar a estrutura dos períodos, além de fazer inferências necessárias à sua compreensão. Dessa forma, pensando em todos esses contextos nos quais as lacunas apareciam e em seus graus de dificuldade, chegamos aos resultados apresentados nessa pesquisa.

Inicialmente, fizemos a contabilização dos erros e acertos de cada um dos participantes dos testes. Após essa etapa, fizemos uma análise comparativa, dos resultados do primeiro teste e do último teste entre os grupos e entre os testes. 


\subsection{Resultados}

Inicialmente, faremos uma análise acerca dos resultados encontrados no primeiro teste. Assim, no gráfico 1, em que são apresentadas as médias em porcentagem de pontos alcançados por cada turma, podemos observar que os alunos das duas turmas alcançaram médias de pontos praticamente iguais. A turma A alcançou uma média de $59,2 \%$ da pontuação total e a turma $\mathrm{B}$ alcançou uma média de $60,1 \%$ da pontuação total.

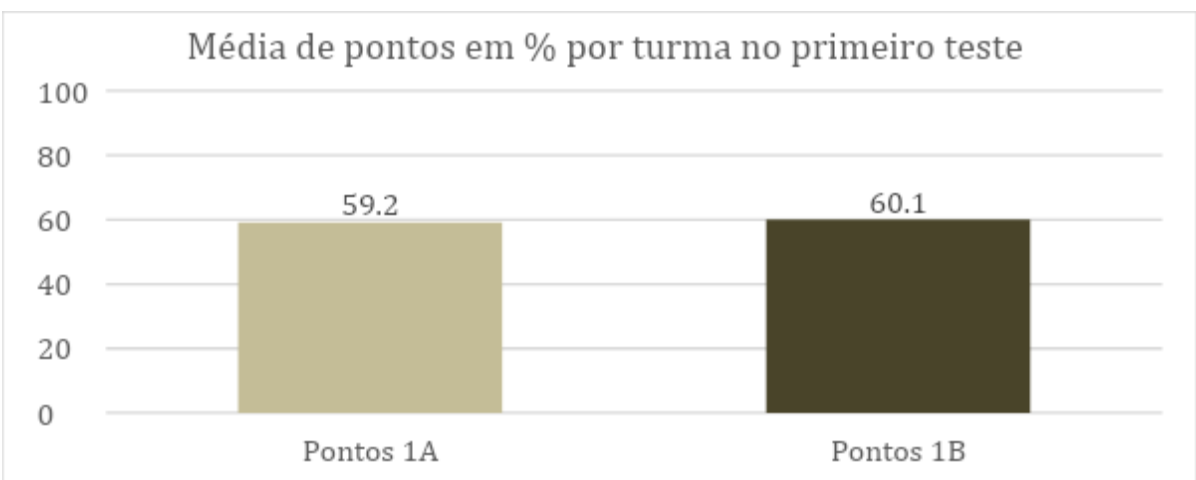

Gráfico 1 - Comparativo das médias de pontos obtidos no primeiro teste nas duas turmas

Apesar de a turma A reunir uma série de condições favoráveis do ponto de vista pedagógico, como todos os alunos dentro da faixa etária esperada para a série, nenhum aluno ter sido reprovado em anos anteriores, ser uma turma sem questões disciplinares que atrapalhasse de forma significativa o desenvolvimento das atividades, podemos observar que a média de pontos não ultrapassou $60 \%$, assim como os resultados encontrados na turma $\mathrm{B}$, que tem um perfil bastante diferente do perfil da turma A. Não houve diferença significativa entre os grupos no primeiro teste.

Após a fase de intervenção que foi feita em uma das turmas, que teve como metodologia interventiva a técnica de Cloze para trabalhar os conteúdos, aplicamos o último teste.

Os resultados do último teste indicam que houve um crescimento acentuado para os alunos que foram expostos à prática de intervenção com a técnica de Cloze. A média de pontos dos alunos da turma $\mathrm{A}$ teve um aumento considerável em relação à média dos resultados do primeiro teste, o que indica que houve um desenvolvimento da habilidade de compreensão leitora.

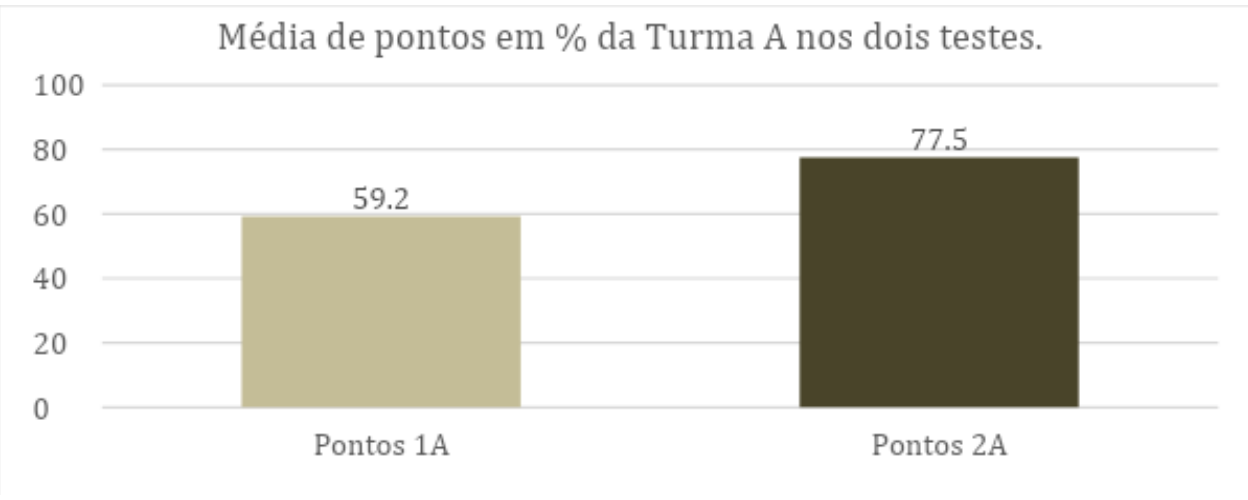

Gráfico 2 - Comparativo das médias de pontos obtidos pela Turma A nos dois testes. 
$\mathrm{O}$ aumento das médias mostrou-se significativa na análise por pares com $\mathrm{T}(22)=6,25$ $\mathrm{p}<0,0001$ e com a análise de variância ANOVA $\mathrm{F}(1,22)=39,0 \mathrm{p}<0,000003$, o que nos dá indícios de que a metodologia interventiva rendeu bons frutos.

Já os resultados do último teste dos alunos da Turma B não apresentaram diferenças em relação ao primeiro teste. A média de pontos obtidos pelos alunos no último teste foi praticamente a mesma do que a obtida no teste 1 .

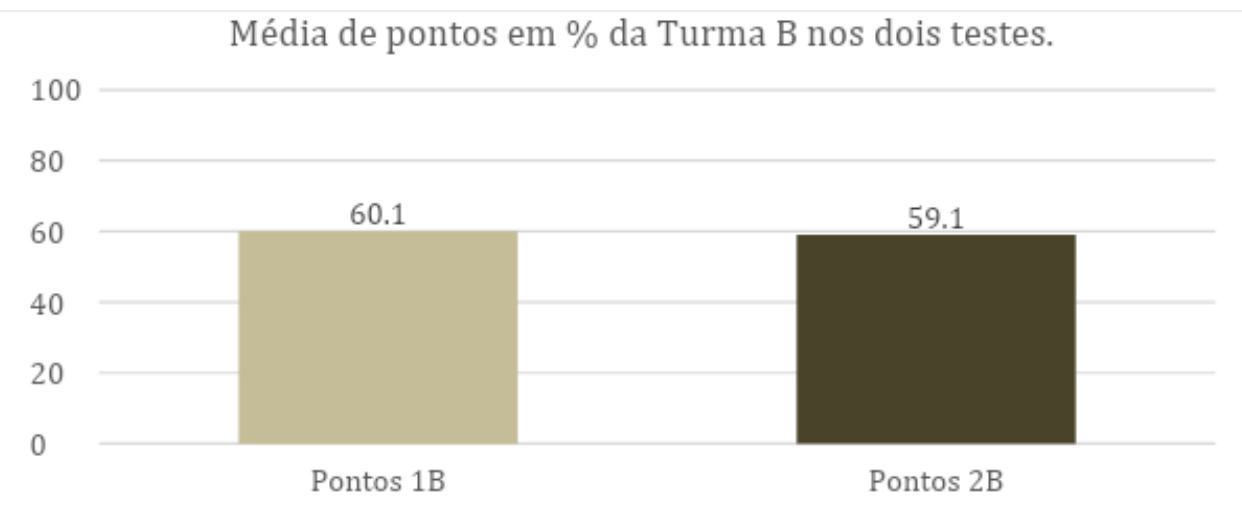

Gráfico 3 - Comparativo das médias de pontos obtidos pela Turma B nos dois testes.

É importante lembrar aqui que essa turma não participou da metodologia interventiva. Os resultados da turma $\mathrm{B}$ no último teste apontam para a eficácia das atividades realizadas na melhoria da compreensão em leitura dos alunos da Turma A. O gráfico 4, abaixo, apresenta o desempenho comparativo entre as turmas nos dois testes.

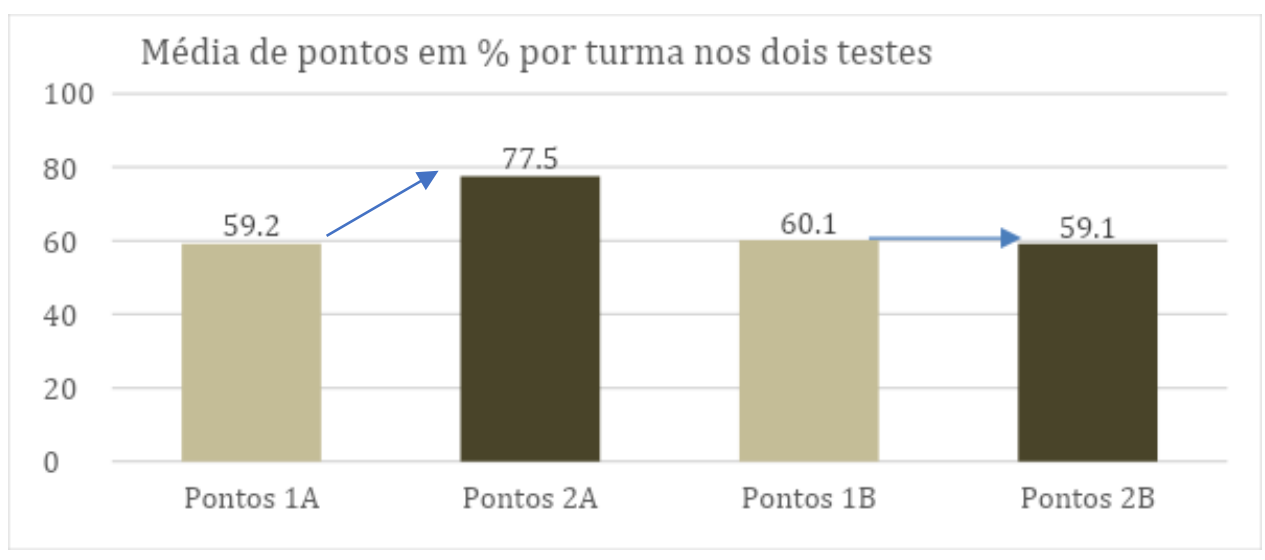

Gráfico 4 - Comparativo das médias de pontos obtidos pelas duas turmas nos dois testes.

Enquanto a Turma B manteve a média de pontos em torno dos $60 \%$ em ambos os testes, a Turma $\mathrm{A}$ teve um crescimento significativo de $18,3 \%$ em relação à média de pontos obtidos no primeiro teste. A média de pontos entre os grupos também se mostrou significativa com o tteste $\mathrm{T}(44)=4,42 \mathrm{p}<0.001$ e com a análise de variância $\operatorname{ANOVA~} \mathrm{F}(1,44)=19,6 \mathrm{p}<0,00006$, tendo sido a Turma A a que conseguiu um melhor desempenho na última tarefa.

Empiricamente, através de observação direta na correção de testes aplicados na turma A notamos uma acentuada melhora no desempenho dos alunos em compreensão de textos 
escritos, especialmente daqueles que, no início da pesquisa, apresentavam mais dificuldade. $\mathrm{O}$ resultado comparativo entre os dois testes de Cloze veio corroborar aquilo que havia sido percebido nas atividades diárias com os alunos, evidenciando a relevância do teste de Cloze como recurso para que haja uma melhora da compreensão em leitura.

Entendemos que o correto preenchimento das lacunas, relaciona-se de maneira estreita com a compreensão local do material escrito e que a compreensão é um processo complexo, pessoal, em que concorrem as informações proporcionadas pelo texto (seu assunto, maior ou menor clareza com que é exposto, estruturas linguísticas que o compõem, etc.) e as habilidades pessoais de leitura do leitor (KATO [1986]2001). A capacidade de decodificação do leitor concorre para a compreensão, uma vez que libera a memória de trabalho para ocupar-se em estabelecer as relações entre as palavras, frases, períodos, parágrafos lidos (MORAIS, 1996).

Isso posto, alinhamo-nos com Perfetti, Landi, Oakhill que ao tratarem da aquisição da habilidade de compreensão em leitura apontam que "Os átomos do significado são extraídos dos períodos, agregados pela leitura de outros períodos do texto e complementados por inferências necessárias para tornar o texto coerente." (PERFETTI, LANDI, OAKHILL, 2013: p. 248). Portanto, a seguir, apresentamos uma breve análise qualitativa de alguns dos itens dos textos utilizados no estudo reportado, de modo a identificar a natureza de certas dificuldades e de certas facilidades dos participantes.

A ideia é mostrar que a compreensão vai exigir uma leitura estrutural do período e uma leitura atenta, de modo a permitir que o aluno faça inferências e/ou releituras em partes dos períodos as quais considere essenciais para atribuir coerência ao texto. Essa análise revela especificidades de cada item (selecionado) e é capaz de mostrar que as habilidades exigidas para completar uma lacuna podem ser de naturezas diferentes.

No texto "A despedida", muitos alunos completaram o item em "...brincar com os amigos, jogar futebol, corrida, pedalar na bicicleta..."com nomes de outras brincadeiras como "queimado", "pique", "vôlei" e também empregaram o verbo "brincar". Não havia, após a lacuna, a vírgula que justificasse completar essa lacuna com outra modalidade de brincadeira ou preposição que justificasse o emprego do verbo "brincar...de". Para completar essa lacuna era necessário ter atenção aos itens anteriores (contexto imediato) e à pontuação, bem como ter o conhecimento do vocabulário de que, nas brincadeiras da infância, "aposta-se corrida" para se chegar à palavra (apostar) que completaria o item como esperado.

No texto "Os dois vasos", em "Um dos vasos rachado e o outro era " para completarem a primeira lacuna (era) os alunos necessitavam da informação contida no período e do auxílio da adição de informação dada na oração que segue a lacuna. Enquanto a segunda lacuna (perfeito) necessitava do contexto imediato anterior e posterior para ser completado com sucesso. A frase após a lacuna, acrescenta a informação que complementa a ideia de que a condição desse vaso era melhor que a do anterior, pois chegava em situação contrária ao outro que chegava meio vazio. "Este último estava sempre (cheio) de água ao fim ___ (da) longa caminhada do riacho (até) a casa, enquanto aquele (rachado) chegava meio vazio." Para o preenchimento da lacuna (cheio) embora necessitasse das informações do contexto do período em que está inserido para ser completado, auxiliam seu correto preenchimento as informações " (cheio) de água" e que o outro vaso chegava sempre "meio vazio". Para a lacuna a ser completada com o item 'rachado' era necessário considerar não só o contexto do início do parágrafo que fornece a informação de que um dos vasos é rachado, mas também da lógica de que a rachadura deixaria passar água, o que ocasionaria a perda d'água.

Os dois testes de Cloze aplicados nas turmas A e B apontaram que, embora a turma A fosse considerada "a melhor da escola", que reunisse uma série de condições favoráveis e que apresentasse, no geral, bons resultados em anos anteriores, apresentou, em termos numéricos, o mesmo desempenho em compreensão leitora que a turma B no primeiro teste, turma 
considerada "dos repetentes", dos alunos "difíceis". Cabe destacar aqui que no início do processo de pesquisa, as duas turmas estavam no mesmo nível, segundo os resultados encontrados com o primeiro teste. Isso nos aponta que em relação ao ponto de partida não houve diferença quantitativa para as duas turmas e, se houve diferença no final da pesquisa, não foi por uma questão de ausência de nivelamento inicial.

Os resultados no desempenho das duas turmas só apresentaram diferença no último teste, aplicado após a intervenção. Esse resultado sugere a importância e a eficácia de se ensinar a ler, de proporcionar atividades em que os alunos possam desenvolver suas habilidades de leitura, por meio da metacognição, da metalinguagem e da consciência sintática. Indicou ainda que mesmo os alunos que tiveram um bom desempenho no pré-teste melhoraram sua pontuação no pós-teste e que também se beneficiaram das ações interventivas.

\section{Considerações Finais}

Neste artigo, apresentamos uma breve revisão da literatura sobre o teste de Cloze na qual fizemos uma descrição de seus aspectos principais. Em seguida, descrevemos a aplicação do teste de Cloze para traçar o rastreio da compreensão leitora dos alunos - antes da intervenção - e para a comparação de resultados - após a intervenção. Atuamos, em sala de aula, com atividades que visavam ao desenvolvimento da compreensão leitora dos alunos e, por fim, analisamos e discutimos os resultados.

$\mathrm{O}$ estudo aqui apresentado sugere que se as atividades de leitura forem realizadas por meio de ensino sistemático com o envolvimento de metacognição, metalinguagem e consciência sintática podem conduzir ao aprimoramento da compreensão leitora. Esse foi o caminho dessa pesquisa, mas não se trata de uma fórmula.

Como percebemos nos resultados, os alunos que experimentaram mais diversidade nas tarefas, que imergiram em práticas de leitura dinâmicas, configuradas em diferentes espaços e momentos, aperfeiçoaram o seu desempenho em compreensão leitora. Por outro lado, os alunos que não participaram da fase interventiva, parecem ter ficado no mesmo patamar e isso não nos causa admiração. Desenvolver a leitura implica não apenas que leiamos em sala, que façamos o aluno ler para responder a um longo questionário sobre o texto, que façamos ler os textos em voz alta, mas implica ensinar o aluno a ler.

Ensiná-lo a exercer controle sobre sua leitura, ou seja, a tomar consciência de que está ou não compreendendo o que está lendo e que isso pode estar de acordo com seus objetivos; ensinar que se lê de maneira diferente textos de diferentes gêneros, ensinar que se pode ler apenas "passando os olhos" pelo texto em busca de uma informação específica, ensinar que se lê também cuidadosamente quando seus objetivos de leitura assim requererem.

Vimos que se faz necessário ensinar a ler durante todos os anos de escolaridade, durante todo o tempo em que o aluno estiver sob o teto da instituição "escola", sendo essa atribuição de todos os professores, um compromisso da escola, uma parte necessária do projeto pedagógico da instituição. Muitas das questões que envolvem dificuldade em leitura e em compreensão do material escrito com as quais nos deparamos nos Anos Finais do Ensino Fundamental, quando o aluno já passou um tempo considerável na escola, aproximadamente seis anos em média, são decorrentes de equívocos metodológicos.

Essas situações de dificuldade acabam, muitas vezes, se aprofundando porque os professores dos Anos Finais do Ensino Fundamental, embora tenham cursado o ensino superior, também apresentam pouco conhecimento científico sobre questões que envolvem a leitura, seu desenvolvimento e seu ensino. Scliar-Cabral (2018) sustenta que a base epistemológica que sustenta as políticas públicas de educação no Brasil relega a segundo plano questões fundamentais como a formação e a valorização do professor. 
Dessa forma, consideramos fundamentais as discussões sobre leitura nos Programas de Formação Continuada para os professores da rede pública. Entendemos que é por meio da postura ativa de um professor que desenvolve habilidades duradouras como a metacognição que o aluno conseguirá lidar com situações novas e com desafios de aprendizagem ao longo da vida. É pela atuação de um professor que desafia seus alunos a explorar o material escrito, o período, a oração e a entender seu funcionamento, que os alunos irão, gradativamente, ganhando autonomia na compreensão leitora e, consequentemente, garantindo uma aprendizagem significativa de leitura.

Esperamos que esse artigo contribua para nortear pesquisas futuras, com a finalidade de que elaborem desenhos experimentais pelos quais seja possível avaliar especificamente o tipo de cognição envolvida, por exemplo, com a utilização de medidas on-line, como argumenta Maia (2018). Por outro lado, esperamos que promova reflexão acerca da prática pedagógica em compreensão leitora, para o trabalho docente de outros professores de Língua Portuguesa ou de qualquer disciplina. Isso aponta para a necessidade de os docentes, em geral, tomarem para si a responsabilidade de desenvolver com seus alunos atividades de leitura que aprimorem a compreensão leitora.

\section{Referências bibliográficas}

ABRAMOVICH, Fanny. Olhos Vermelhos. 1. ed. São Paulo: Moderna, 1995. 48 p.

ABREU, Kátia Nazareth Moura de; CID DE GARCIA, Daniela; HORA, Katharine de Freitas P.N. da; SOUZA, Cristiane Ramos de. O teste de Cloze como instrumento de medida de proficiência em leitura: fatores linguísticos e não linguísticos. Revista de Estudos da Linguagem, Minas Gerais: UFMG, v. 25, p. 1767 - 1799, 2017.

ABREU, Kátia; Hora, Katharine da. O desenvolvimento da compreensão leitora: Cloze e atividades práticas no ensino fundamental. In: MAIA, Marcus (org.) Psicolinguística e Metacognição na escola. Campinas, SP: Mercado de Letras, 2019ª cap. VII. p. 179-202.

ALLIENDE, Felipe e CONDEMARÍN, Mabel. A leitura: teoria, avaliação e desenvolvimento. Porto Alegre: Artmed, 2005. 215 p.

BRASIL. Base Nacional Comum Curricular (BNCC). Educação é a Base. Brasília, MEC, 2017. Disponível em http://basenacionalcomum.mec.gov.br/images/BNCC publicacao.pdf. Acesso em: 01 jul. 2020.

BRASIL. Relatório SAEB [recurso eletrônico]. 2017. Brasília, DF: INEP, 2019.

CAIN, Kate. (2007) Syntactic awareness and reading ability: Is there any evidence for a special relationship? Applied Psycholinguistics, 28 (4), 679-694. DOI: 10.1017/S0142716407070361. CAPOVILLA, Alessandra Gotuzo Seabra; CAPOVILLA, Fernando César; SOARES, Joceli Vergínia Toledo. Consciência sintática no ensino fundamental: correlações com consciência fonológica, vocabulário, leitura e escrita. Psico-USF (Impr.) Itatiba, v. 9, n. 1, p. 39-47, June 2004.

CUNHA, Maria Antonieta Antunes. Literatura Infantil: teoria \& prática. 11. ed. São Paulo, Editora Ática, 1991. $176 \mathrm{p}$.

DUBAY, William H. The Principles of Readability. Costa Mesa, California: Impact Information: $2004.77 \mathrm{p}$.

FONSECA, Rochele Paz; CASARIN, Fabiola Schwengber; OLIVEIRA, Camila Rosa de; GINDRI, Gigiane; ISHIGAKI, Ellen Cristina Siqueira Soares; ORTIZ, Karin Zazo; PARENTE, Maria Alice de Mattos Pimenta; SCHERER, Lilian Cristine. Adaptação de instrumentos neuropsicológicos verbais: um fluxograma de procedimentos para além da tradução. Interação em Psicologia, Universidade Federal do Paraná, v.15, n. especial, p.59-69, 2011. https://doi.org/10.5380/psi.v15i0.25374. 
GOMBERT, Jean Émile. Metalinguistic development. Chicago: University of Chicago Press, 1992. 246 p.

GOMES, Neidiane Soares; AUDI, Luciana C. C. O ensino de língua inglesa com textos autênticos. Revista Eletrônica Pro-Docência / UEL. Edição N.3, Vol. 1, jan-jun. 2013. Disponível em http://www.uel.br/revistas/prodocenciafope. p. 117-122.

JOLY, Maria Cristina Rodrigues Azevedo; BONASSI, Jaqueline; DIAS, Anelise Silva; PIOVESAN, Nayane Martoni; SILVA, Diego Vinicius da. Avaliação da Compreensão de Leitura pelo Sistema Orientado de Cloze (SOC). Fractal: Revista de Psicologia, Universidade Federal Fluminense, v. 26, n.1, p.223-242, jan./abr. 2014.

KATO, Mary. A. 1986. No mundo da escrita: uma perspectiva psicolinguística. São Paulo: Ática, 2001. $144 \mathrm{p}$.

KATO, Mary A. 1985. O aprendizado da leitura. 2. ed. São Paulo: Martins Fontes, 1987. $121 \mathrm{p}$.

KENEDY, Eduardo. Psicolinguística na Descrição Gramatical. In: MAIA, Marcus (org.). Psicolinguística, psicolinguísticas: uma introdução. São Paulo: Contexto, 2015. 208p. KLEIMAN, Angela. Oficina de leitura: teoria e prática.10 edição, Campinas, SP: Pontes, 2004.

KINTSCH, Walter e RAWSON, Katherine A. Compreensão. In: SNOWLING, M. J.; HULME, C. (orgs.). A ciência da leitura. Tradução Ronaldo Cataldo Costa. Porto Alegre: Penso, 2013, p. 227-244.

MAIA, Marcus (org.). Psicolinguística e Educação. Campinas, SP: Mercado de Letras, 2018. $258 \mathrm{p}$.

MAIA, Marcus (org.) Psicolinguística e Metacognição na escola. Campinas, SP: Mercado de Letras, 2019a. 239 p.

MAIA, Marcus. Pensando (psico)linguisticamente, experimentalmente, educacionalmente. In: PILATI, Eloisa. NAVES, Rozana, SALLES, Heloisa (orgs.) Novos olhares para a gramática na sala de aula: questões para estudantes, professores e pesquisadores. Campinas: Pontes, 2019b. cap. 4. p. 93-118.

MORAIS, José. A arte de ler. Tradução Álvaro Lorencini. São Paulo: Editora UNESP, 1996. $327 \mathrm{p}$.

OS DOIS VASOS. Disponível em: $<$ http://www.itatiaia.com.br/blog/jose-lino-souza-barros. Acesso em 11 de julho de 2017.

PERFETTI, Charles A. Reading Skills. N.J. Smelser \& P. B. Baltes (Eds.). International encyclopedia of the social \& behavioral sciences (pp.12800-12805). Oxford: Pergamon, 2001.

PERFETTI, Charles A.; LANDI, Nicole; OAKHILL, Jane. A aquisição da habilidade de compreensão da leitura. In: SNOWLING, M. J.; HULME, C. (orgs.). A ciência da leitura. Tradução Ronaldo Cataldo Costa. Porto Alegre: Penso, 2013. cap. 13, p. 245-265.

PERFETTI, Charles A. \& ADLOF, Suzanne M. Reading Comprehension: a conceptual framework from word meaning to text meaning. In: SABATINI, John P., ALBRO, Elizabeth R., O'REILLY, Tenaha. Measuring up. Maryland: Rowman \& Littlefield education, 2012. cap. 1, p.3-20.

PILATI, Eloisa. Linguística, Gramática e Aprendizagem Ativa. Campinas, SP: Pontes Editores, $2^{\mathrm{a}}$ edição, 2017. 145 p.

PINHEIRO, Ana C. Compreensão em leitura no sétimo ano do ensino fundamental: um estudo com o Cloze. (Dissertação) Mestrado Profissional em Letras - Faculdade de Formação de Professores, UERJ. São Gonçalo, 117p. 2018.

POERSCH, José Marcelino. Uma questão terminológica: consciência, metalinguagem, metacognição. Letras de Hoje. Porto Alegre, v. 33, no 4, p. 7-12, dezembro de 1998. 
Volume 15 - Número 2 - ago/dez de 2020

RIBEIRO, C. Metacognição: um apoio ao processo de aprendizagem. Psicologia: reflexão e crítica, Porto Alegre, 16 (1), p. 109-116, 2003.

ROSA, Maria Carlota. 2000. Introdução à Morfologia. 2ed. São Paulo: Contexto, 2002. 157 p.

SANTOS, Thais Vargas dos. Consciência sintática e desempenho em leitura e escrita. ALFAL 2014, p. 1952-1965.

SANTOS, Acácia Aparecida Angeli dos; PRIMI, Ricardo; TAXA, Fernanda de O.S.; VENDRAMINI, Claudette M. M. O teste de cloze na avaliação da compreensão em leitura. Psicologia: reflexão e crítica, Rio Grande do Sul: UFRGS, 15(3), p. 549-560, 2002.

SANTOS, Acácia Aparecida Angeli dos; BORUCHOVITCH, Evely; OLIVEIRA, Katya Luciane de (orgs). Cloze: um instrumento de diagnóstico e intervenção. São Paulo: Casa do Psicólogo, 2009. 348 p.

SANTOS, Acácia Aparecida Angeli dos; BORUCHOVITCH, Evely; OLIVEIRA, Katya Luciane de. Análise da fidedignidade entre dois tipos de pontuação: técnica de Cloze. Psicologia em Pesquisa, UFJF, 1 (01), p. 41-51, janeiro-junho, 2007.

SCLIAR-CABRAL, Leonor. Inter-relação entre o biológico e o cultural: psicolinguística e educação, In: MAIA, M. (org.) Psicolinguística e Educação. Campinas: Mercado de Letras. 2018. p. 25-55.

SOLÉ, Isabel. Estratégias de leitura. Porto Alegre: Penso, 1998. 194 p.

SPINILLO, Alina Galvão; MOTA, Márcia Maria Peruzzi Elia da; CORREA, Jane. Consciência metalinguística e compreensão de leitura: diferentes facetas de uma relação complexa. Educar Em Revista, Curitiba: Editora UFPR, n. 38, p. 157-171, set./dez. 2010.

TAYLOR, Wilson L. Cloze procedure: a new tool for measuring readability. Journalism Quarterly, Questia Trusted Online Research, v. 30, p. 415-433, 1953. 